\title{
Cow- and herd-level risk factors for on-farm mortality in Midwest US dairy herds
}

\author{
M. Q. Shahid,* J. K. Reneau, $†$ H. Chester-Jones, $†$ R. C. Chebel, $\ddagger$ and M. I. Endres ${ }^{1}$ \\ *Department of Livestock Production, University of Veterinary and Animal Sciences, Lahore, Pakistan \\ †Department of Animal Science, and \\ ‡Department of Veterinary Population Medicine, University of Minnesota, St. Paul 55108
}

\section{ABSTRACT}

The objectives of this study were to describe on-farm mortality and to investigate cow- and herd-level risk factors associated with on-farm mortality in Midwest US dairy herds using lactation survival analysis. We analyzed a total of approximately 5.9 million DHIA lactation records from 10 Midwest US states from January 2006 to December 2010. The cow-level independent variables used in the models were first testday milk yield, milk fat percent, milk protein percent, fat-to-protein ratio, milk urea nitrogen, somatic cell score, previous dry period, previous calving interval, stillbirth, calf sex, twinning, calving difficulty, season of calving, parity, and breed. The herd-level variables included herd size, calving interval, somatic cell score, 305-d mature-equivalent milk yield, and herd stillbirth percentage. Descriptive analysis showed that overall cow-level mortality rate was 6.4 per 100 cow-years and it increased from 5.9 in 2006 to 6.8 in 2010. Mortality was the primary reason of leaving the herd $(19.4 \%$ of total culls) followed by reproduction (14.6\%), injuries and other (14.0\%), low production (12.3\%), and mastitis $(10.5 \%)$. Risk factor analysis showed that increased hazard for mortality was associated with higher fatto-protein ratio (>1.6 vs. 1 to 1.6), higher milk fat percent, lower milk protein percent, cows with male calves, cows carrying multiple calves, higher milk urea nitrogen, increasing parity, longer previous calving interval, higher first test-day somatic cell score, increased calving difficulty score, and breed (Holstein vs. others). Decreased hazard for mortality was associated with higher first test-day milk yield, higher milk protein, and shorter dry period. For herd-level factors, increased hazard for mortality was associated with increased herd size, increased percentage of stillbirths, higher somatic cell score, and increased herd calving interval. Cows in herds with higher milk yield had lower mortality hazard. Results of the study indicated that first test-day

Received June 23, 2014.

Accepted March 31, 2015.

${ }^{1}$ Corresponding author: miendres@umn.edu records, especially those indicative of negative energy balance in cows, could be helpful to identify animals at high risk for mortality. Higher milk yield per cow did not have a negative association with mortality. In addition, the association between herd-level factors and mortality indicated that management quality could be an important factor in lowering on-farm mortality, thereby improving cow welfare.

Key words: cow mortality, risk factors

\section{INTRODUCTION}

On-farm dairy cow mortality is a growing problem in the dairy industry and has a significant effect on dairy farm profitability. It can cause economic losses due to decreased milk production, loss of income from animal sales, treatment cost during the period of illness before death, increased replacement costs, extra labor, and the cost of dead animal disposal (Thomsen et al., 2006a). In addition, an increase in herd mortality indicates suboptimal health and compromised welfare (Thomsen and Houe, 2006). Mortality is an important routinely collected herd variable associated with dairy cattle welfare and has been included in recent welfare assessment protocols for dairy cows (EFSA, 2012).

It is not known what should be considered a normal level for on-farm dairy cow mortality. Thomsen and Houe (2006) reviewed 19 studies that described dairy cow mortality from 1965 to 2006 and found that the average mortality was in the range of 1 to $5 \%$. In the United States, dairy cow mortality remained at 1 to 2\% from 1930 to 1990 (Shahid, 2013). However, recent studies indicated relatively higher mortality rates. Pinedo et al. (2010) studied 2,054 DHIA herds from 38 US states and found a $6.6 \%$ mortality rate (MR) for cows that calved from 2001 to 2006. Similarly, Alvåsen et al. (2012) documented that mortality in Swedish dairy herds gradually increased from $5.1 \%$ in 2002 to 2003 to $6.6 \%$ in 2009 to 2010 . Mortality has become the primary reason for culling at dairy farms $(20.6 \%$ of total culls; Pinedo et al., 2010), thereby increasing concerns about dairy cow welfare. 
Recent studies investigating risk factors for mortality mainly focused on herd characteristics and management style. However, very few studies examined the relationship between cow attributes and mortality risk. Cow mortality increased with larger herd size, longer herd calving interval, the use of TMR, higher herd SCC (Alvåsen et al., 2012), lower yearly culling rate, and herds with higher proportion of purchased cows (Raboisson et al., 2011). Mortality was lower in herds with higher milk yield and access to pasture for grazing (Alvåsen et al., 2012). At the cow level, higher mortality was associated with lower milk yield (Pinedo et al., 2010) and increasing parity (Raboisson et al., 2011). Conversely, Miller et al. (2008) reported that death frequency increased with greater milk yield. Considering the effect of mortality on cow welfare and profitability, further research is needed to explore the cow attributes associated with higher mortality taking into account herd characteristics. The objectives of the current study were to describe the recent trends in mortality in DHIA member herds in the Midwestern United States and to investigate cow- and herd-level risk factors associated with on-farm mortality.

\section{MATERIALS AND METHODS}

\section{Study Data}

The data consisted of 5,899,732 DHIA lactation records of cows (from January 1, 2006 to December 31, 2010) from 10 Midwest states (Minnesota, Wisconsin, Illinois, Iowa, Indiana, Michigan, Ohio, Nebraska, North Dakota, and South Dakota) and were obtained from Dairy Records Management Systems (DRMS, Raleigh, NC). The lactation records included information for herd code, cow registration number, breed, calving date, parity, variables related to milk yield [test day, 305-d mature equivalent (305ME), peak], milk composition (fat percent, protein percent, SCC), dry period length, date of removal from the herd, and removal code. Records with missing values on calving date and from herds with herd size $<20$ cow-years $(0.02$ million records) were removed from the data set before analysis.

\section{Variables of Interest}

Outcome Variable. The outcome variable was lactation ended by on-farm death, reported to DHIA, and was expressed as mortality rate (MR). The MR was calculated as number of cows that died during a time period divided by the total number of cow-years at risk during that duration (Pinedo et al., 2010; Raboisson et al., 2011). The number of cow-years was calculated by adding all the cow-days $(1$ cow-day $=1$ cow on a farm for $1 \mathrm{~d}$ ) during a specific time period divided by 365.25 d (0.25 was added to account for leap year).

Explanatory Variables. The MR for year, parity, lactation stage, and season was estimated for descriptive analysis. The years included 2006, 2007, 2008, 2009, and 2010. Parity was categorized into 1, 2, 3, 4, and $\geq 5$. Lactation stage was categorized as $\leq 40,41$ to 99, 100 to 199, 200 to 305, and $\geq 306$ DIM. Season was divided into 4 categories: spring (March to May), summer (June to August), fall (September to November), and winter (December to February).

For risk factor analysis, various cow- and herd-level explanatory variables were estimated from lactation records. The variables were related to different management areas such as milk production, transition cow management, milking management, reproductive management, and cow and herd characteristics (Table 1). These areas were considered important for our evaluation of risk factors for mortality and were available in the data set.

Cow-level explanatory variables included first testday milk yield (1st MY), milk fat percent, milk protein percent, fat-to-protein ratio (FPR), MUN, SCS, calving difficulty, calf sex, calving with stillbirth, twinning, previous calving interval (PCI), previous lactation dry period length (PDP), parity, breed, and season of calving. The 1st MY was expressed as a relative value from the mean on a herd year-season basis and was categorized into 3 levels: low, cows producing $<1$ standard deviation (1 SD) below the herd-year-season average (<mean - $1 \mathrm{SD})$; middle, cows producing between $1 \mathrm{SD}$ below and $1 \mathrm{SD}$ above the herd year-season average (mean $\pm 1 \mathrm{SD}$ ); and high, cows producing above $1 \mathrm{SD}$ of the herd year-season average (>mean $+1 \mathrm{SD})$. Similarly, milk fat and protein percent were categorized into 3 classes, low, middle, and high, on a herd year-season basis. The FPR was categorized into 3 groups: low $(\mathrm{FPR}<1)$, middle $(\mathrm{FPR}=1.0-1.6)$, and high (FPR >1.6). To exclude the transition milk period, we only used observations for DIM $>5$ for fat percent, protein percent, and FPR. Milk urea $\mathrm{N}$ was expressed as a relative value from the mean on the herd year-season basis and divided into 3 levels: low, MUN value of 6 points below the herd-year-season average $(<$ mean -6$)$; middle, MUN between 6 points below and 6 points above the herd year-season average (mean \pm 6$)$; and high, MUN value 6 points above the herd year-season average $(>$ mean +6$)$. A value of 6 was used to accommodate the normal range of MUN values within the same group of cows (DRMS, 2012). Cow SCS was categorized into 5 groups based on DRMS classification: $\leq 3.0,3.1$ to $4.9,5.0$ to $5.9,6.0$ to 6.9 , and $\geq 7.0$. Calving difficulty was expressed into 
Table 1. Explanatory variables for risk factor analysis of on-farm mortality in Midwest DHIA dairy herds

\begin{tabular}{lll}
\hline Main area & Explanatory variables & Variable type \\
\hline Herd characteristics & Herd size (cow years) & Categorical \\
& Herd 305-d mature equivalent milk yield & Categorical \\
& Herd calving interval (mo) & Categorical \\
& Herd stillbirth (\%) & Categorical \\
Milk production & Herd SCC & Categorical \\
Reproduction & First test-day milk yield (kg) & Categorical \\
& Previous calving interval (mo) & Continuous \\
& Calving difficulty (on a scale 1-5) & Categorical \\
Transition cow management & Twinning & Categorical \\
& Calf sex & Categorical \\
& Fat-to-protein ratio & Categorical \\
& Milk fat \% & Categorical \\
& Milk protein \% & Categorical \\
& MUN & Categorical \\
Genetics & Previous lactation dry period (d) & Categorical \\
Milking management & Calving started with stillbirth & Categorical \\
Cow attributes & Breed & Categorical \\
& First test-day SCC & Categorical \\
& Parity & Categorical \\
& DIM & Continuous \\
\hline
\end{tabular}

5 categories: 1 , no problem at calving, to 5 , extreme difficulty. Calf sex was expressed as male or female. Twinning was expressed as yes (lactation started with calving $>1$ calf) and no (lactation started with calving single calf). Stillbirth was expressed in 2 categories: yes (lactation started with stillbirth), and no (lactation started with live calf). Previous calving interval was treated as a continuous variable in months. The records with calving interval $\leq 9$ mo were excluded from the analysis. The PDP was categorized into 3 groups: short ( $\mathrm{PDP} \leq 30 \mathrm{~d})$, middle (PDP $=31-70)$, and long (PDP $>70$ ). Breed category was divided into Holstein, Jersey, Brown Swiss, Ayrshire, Guernsey, crossbred, and all others as the last category.

Herd-level variables were herd size, herd-level stillbirth percent (HSB), average herd calving interval (HCI), herd 305ME milk yield (HMY), and herd SCS (HSCS). Herd size was expressed into 4 categories: small (20-99 cow-years), medium (100-199), medium large (200-499), and large $(\geq 500)$. The HSB was expressed into 4 categories: low $(\leq 5 \%)$, medium low (6-15\%), medium high (16-25\%), and high (>25\%). The HCI was categorized into 3 classes: 12 to 14 mo, 15 to $16 \mathrm{mo}$, and $>16 \mathrm{mo}$. The HMY was expressed into 4 groups: high $(\geq 11,364 \mathrm{~kg})$, medium high $(\geq 9,546-11,363$ $\mathrm{kg})$, medium low $(\geq 7,727-9,545 \mathrm{~kg})$, and low $(<7,727$ $\mathrm{kg}$ ). Herd SCS was categorized into 5 groups and was expressed as: low $(\leq 2)$, low medium $(2.1-2.5)$, medium (2.6-3.0), medium high (3.1-3.5), and high $(\geq 3.6)$. The categories for herd milk yield, SCS, and calving interval were derived from the Minnesota DHI yardstick (MNDHIA, 2011). The change in herd size during the study period was also estimated and expressed into 3 categories: constant size herds ( $\pm 10 \%$ yearly change), expand- ing size herds ( $>10 \%$ yearly increase), and decreasing size herds ( $>10 \%$ yearly decrease).

\section{Statistical Analysis}

Data were analyzed using SAS (version 9.2; SAS Institute Inc., Cary, NC). The frequency distribution of lactation records and herds by state, size, and production level was obtained using the FREQ Procedure. The range of herd level MR was estimated by UNIVARIATE Procedure.

Survival analysis was performed to evaluate the association between mortality and different cow- and herd-level risk factors using Cox Proportional Hazards regression. Follow-up time started at calving and ended next calving or removal from the herd. The event was the lactation ended by on-farm mortality (1), whereas the records which ended when cow exited the herd because of reasons other than mortality or entered into next lactation were censored (0). The regression models were fitted applying the PROC PHREG procedure of SAS (version 9.2). First the univariate analysis was performed. The variables with $P$-value $\leq 0.2$ in univariate analysis were considered for inclusion in the multivariate model. The initial model was mortality hazard $=$ baseline hazard $\times \exp (1$ st MY + fat percent + protein percent $+\mathrm{FPR}+\mathrm{MUN}+\mathrm{SCS}+\mathrm{PDP}+$ $\mathrm{PCI}+$ stillbirth + calf sex + twinning + calving difficulty + season of calving + parity + breed + herd size + herd calving interval + HMY + HSB + HSCS), where baseline hazard is an unspecified hazard function and exp is the exponent function. The explanatory variables have been described previously. To avoid the effect of collinearity between explanatory variables, 
Table 2. Distribution of dairy herds by state, herd size, and milk yield in Midwest DHIA data set

\begin{tabular}{lc}
\hline Category & Total herds $(\%)$ \\
\hline State $(\mathrm{n}=7,188)$ & \\
Minnesota & 34.3 \\
Wisconsin & 12.1 \\
Ohio & 12.3 \\
Iowa & 12.2 \\
Michigan & 11.2 \\
Illinois & 6.7 \\
Indiana & 6.1 \\
South Dakota & 2.3 \\
Nebraska & 2.2 \\
North Dakota & 0.7 \\
Herd size, no. of cow-years ${ }^{1}(\mathrm{n}=7,188)$ & 64.6 \\
20 to 99 & 21.0 \\
100 to 199 & 10.0 \\
200 to 499 & 4.0 \\
$\geq 500$ & 26.9 \\
Herd $305 \mathrm{ME}{ }^{2}$ milk yield, $\mathrm{kg}(\mathrm{n}=7,064)$ & 44.5 \\
$\geq 11,364$ & 28.5 \\
$\geq 95,46$ to $<11,364$ & 15.8 \\
$\geq 7,727$ to $<9,546$ & \\
$<7,727$ & \\
\hline
\end{tabular}

${ }^{1} \mathrm{~A}$ cow-year means 1 cow that stayed in the herd for $1 \mathrm{yr}$.

${ }^{2} 305 \mathrm{ME}=305$-d mature equivalent.

related variables were not analyzed in the same model. Because FPR was estimated from milk fat and protein percent, its association with mortality was estimated in a separate model. Similarly, stillbirth and HSB, calving difficulty and calf sex, as well as dry period and calving interval were analyzed separately to avoid confounding. Among correlated variables, the one used in the final model was the one that had the better fit of the data shown by likelihood ratio statistics. For PCI and PDP, separate models were run with records for parity $\geq 2$. In addition, a separate model was used to investigate the association of MUN with mortality because MUN values were available only for the year 2010. All the additional models included the same explanatory variables as described previously (as appropriate). The interaction of 1st MY with FPR, parity, and breed was also tested.

\section{RESULTS}

\section{Data Set Characteristics and Descriptive Statistics}

A total of 5,880,840 lactation records from 7,188 herds were available for analysis. The majority of herds were from Minnesota $(34.3 \%)$ followed by Ohio $(12.3 \%)$, Wisconsin (12.1\%), Iowa (12.1\%), and Michigan $(11.2 \%)$, as shown in Table 2. All DHIA herds from the states included in the study (except for Wisconsin) were being processed at DRMS. The percent of cow population on DHI from each state in 2010 was: Illinois,
Table 3. Distribution of lactation records by parity and herd size in Midwest DHIA dairy herds (data from January 2006 to December $2010 ;$ no. of lactations $=5.9$ million)

\begin{tabular}{lc}
\hline Variable & Total lactation records $(\%)$ \\
\hline Parity & \\
1 & 37.5 \\
2 & 26.9 \\
3 & 17.3 \\
4 & 9.7 \\
$\geq 5$ & 8.5 \\
Herd size & \\
20 to 99 & 24.8 \\
100 to 199 & 21.0 \\
200 to 499 & 22.5 \\
$\geq 500$ & 31.7 \\
\hline
\end{tabular}

46\%; Indiana, 27\%; Iowa, 60\%, Michigan, 47\%, Minnesota, 54\%; Nebraska, 46\%; North Dakota, 35\%; Ohio, 42\%; South Dakota, 40\%; and Wisconsin, 51\% (J. Clay, DRMS, Raleigh, NC, personal communication).

Average herd size was $140 \pm 266$ (mean \pm SD) cowyears with a median value 74 cow-years, indicating skewed distribution of herd size. Herds with 20 to 99 cow-years were highest in number $(65 \%$ of total herds) followed by herd size 100 to 199 (21\%) and 200 to 499 $(10 \%)$. Larger herds with $\geq 500$ cow-years were only $4 \%$ of total herds in the data set. However, lactation records were evenly distributed among different herd size groups (Table 3). The frequency of herds with milk production $\geq 9,546$ to $<11,364 \mathrm{~kg}$ was highest (44.5\% of total herds) followed by herds with milk yield level $\geq 7,727$ to $<9,546 \mathrm{~kg}(28.5 \%)$ and herds with milk production level $\geq 11,364 \mathrm{~kg}(26.9 \%)$. The lactation records for parity 4 or greater were relatively small (18\%) compared with parity 1 (37.5\%; Table 3$)$.

\section{Descriptive Statistics of Mortality}

The overall MR for the period 2006 to 2010 was $6.4 \%$ (per 100 cow-years). An increase in cow-level MR from 5.9 in 2006 to 6.8 in 2010 was observed (Table 4). Mortality rate was high (20.5) in early lactation ( $\leq 40$ DIM) compared with mid- (100-199 DIM) and late lactation (200-305 DIM) with MR of 3.5 and 3.6, respectively (Table 4). Frequency distribution of mortality in the first $40 \mathrm{~d}$ after calving showed that the proportion of deaths was greatest in the first 10 to $15 \mathrm{~d}$ after calving (Figure 1). The herd-level annual MR ranged from 0 to 95.2 ( 1 herd, 1 yr). Herds with zero mortality were about $10 \%$ of total herds in the study across the years. Herds with $\mathrm{MR} \geq 10$ were in the 85 th percentile and above (Table 5). Mortality was the primary reason for leaving the herd (19.4\% of total culls), as shown in Table 6 . 
Table 4. Cow-level mortality rates by year, season, lactation stage, and parity in Midwest DHIA dairy herds (data from January 2006 to December 2010; no. of lactations $=5.9$ million)

\begin{tabular}{lc}
\hline Variable & $\begin{array}{c}\text { Mortality rate } \\
\text { (per 100 cow-years) }\end{array}$ \\
\hline Overall mortality & 6.4 \\
Year & \\
2006 & 5.9 \\
2007 & 6.2 \\
2008 & 6.7 \\
2009 & 6.4 \\
2010 & 6.8 \\
Season & \\
March-May & 6.1 \\
June-August & 6.6 \\
September-November & 6.1 \\
December-February & 6.8 \\
Lactation stage (DIM) & \\
$\leq 40$ & 20.5 \\
$41-99$ & 5.0 \\
$100-199$ & 3.5 \\
$200-305$ & 3.6 \\
$\geq 306$ & 4.6 \\
Parity & \\
1 & 3.5 \\
2 & 5.2 \\
3 & 8.5 \\
4 & 11.0 \\
$\geq 5$ & 13.6 \\
\hline
\end{tabular}

\section{Cow-Level Risk Factors}

Milk Yield, FPR, Fat Percent, and Protein Percent. First test-day milk yield was associated with on-farm mortality. Within herd, high-producing cows (>mean $+1 \mathrm{SD})$ had $5 \%$ lower risk of mortality [hazard ratio $(\mathbf{H R})=0.95 ; 95 \% \mathrm{CI}=0.94-0.96]$ than cows with average milk yield (mean $\pm 1 \mathrm{SD}$; Table 7 ). Conversely, cows with lower 1st MY (<mean $-1 \mathrm{SD})$ had $51 \%$ greater mortality risk $(\mathrm{HR}=1.52 ; 95 \% \mathrm{CI}=$ $1.50-1.54)$ than cows with average milk yield. The FPR was associated with on-farm mortality. Cows with high FPR $(>1.6)$ at the first test day had $43 \%$ greater mortality risk $(\mathrm{HR}=1.43 ; 95 \% \mathrm{CI}=1.41-1.45)$ than cows

Table 5. Distribution of yearly herd-level mortality rates for Midwest DHIA herds (data from January 2006 to December 2010 for 7,188 herds)

\begin{tabular}{lcc}
\hline Quartile & Percentile & Mortality rate (\%) \\
\hline Minimum & 0 & 0.0 \\
& 1 & 0.0 \\
First quarter & 5 & 0.0 \\
Median & 10 & 0.0 \\
Third quarter & 25 & 2.2 \\
& 50 & 4.8 \\
& 75 & 8.0 \\
Maximum & 85 & 10.0 \\
& 90 & 11.6 \\
& 99 & 22.0 \\
& 100 & 95.2 \\
\hline
\end{tabular}

with average FPR (1.0-1.6). The interaction analysis of FPR with 1st MY showed that cows with high FPR at the first test day had $32 \%(\mathrm{HR}=1.32 ; 95 \% \mathrm{CI}=$ $1.29-1.33)$ and $108 \%(\mathrm{HR}=2.08 ; 95 \% \mathrm{CI}=2.03-2.13)$ greater mortality risk than cows with average FPR for middle- (mean $\pm 1 \mathrm{SD})$ and low-producing $(<$ mean -1 $\mathrm{SD})$ cows, respectively. However, cows with high FPR had only $6 \%$ greater $(\mathrm{HR}=1.06 ; 95 \% \mathrm{CI}=1.4102-1.0)$ mortality risk than cows with average FPR among high-producing cows (Table 8). Both high and low milk fat percent was associated with mortality. Cows with high fat percent $(>$ mean $+1 \mathrm{SD})$ at the first test day had $43 \%$ greater mortality risk $(\mathrm{HR}=1.43 ; 95 \% \mathrm{CI}=$ 1.36-1.40) than cows with average fat percent (mean $\pm 1 \mathrm{SD}$ ), as shown in Table 7 . In addition, cows with low fat percent (<mean - 1 SD) had $14 \%$ lower risk compared with cows with average fat percent at the first test day. Low milk protein percent at the first test day was significantly associated with mortality. Cows with low milk protein percent (<mean - 1 SD) had $38 \%$ greater mortality risk $(\mathrm{HR}=1.38 ; 95 \% \mathrm{CI}=1.36-1.40)$ than cows with average milk protein percent (mean \pm $1 \mathrm{SD})$.

SCS and MUN. Cows with elevated MUN values $(>$ mean +6$)$ at the first test day had $14 \%$ higher mortality hazard $(\mathrm{HR}=1.14 ; 95 \% \mathrm{CI}=1.10-1.18)$ than cows with MUN values within normal range (mean \pm $6)$. Low MUN was also associated with increased mortality (Table 7). Mortality risk increased with higher SCS. Cows with SCS $\geq 6.9,5$ to $6.9,4$ to 5 , and 3 to 3.9 had $27,17,15$, and $10 \%$ greater risk of mortality than cows with SCS $\leq 3.0$, respectively (Table 7 ).

Dry Period and Calving Interval. Previous dry period was significantly associated with mortality. Mortality hazard was $6 \%$ less $(\mathrm{HR}=0.94 ; 95 \% \mathrm{CI}=$ 0.91-0.96) for cows with short PDP ( $\leq 30 \mathrm{~d})$ than cows with average PDP (31-70 d). However, cows with longer PDP $(>70 \mathrm{~d})$ had $8 \%$ greater mortality risk than cows with reference dry period $(31-70 \mathrm{~d})$, as shown in Table 7.

Table 6. Frequency distribution of culling with DHIA reported removal codes (data from January 2006 to December 2010 for 7,188 herds, total culling events $=1.62$ million)

\begin{tabular}{lc}
\hline Reasons of culling & Total culls (\%) \\
\hline Mortality & 19.4 \\
Injuries and others & 14.0 \\
Reproductive problems & 14.6 \\
Low production & 12.3 \\
Mastitis & 10.5 \\
Dairy & 9.3 \\
Feet and leg & 5.6 \\
Disease & 4.8 \\
Udder problems & 2.3 \\
Not reported & 7.2 \\
\hline
\end{tabular}




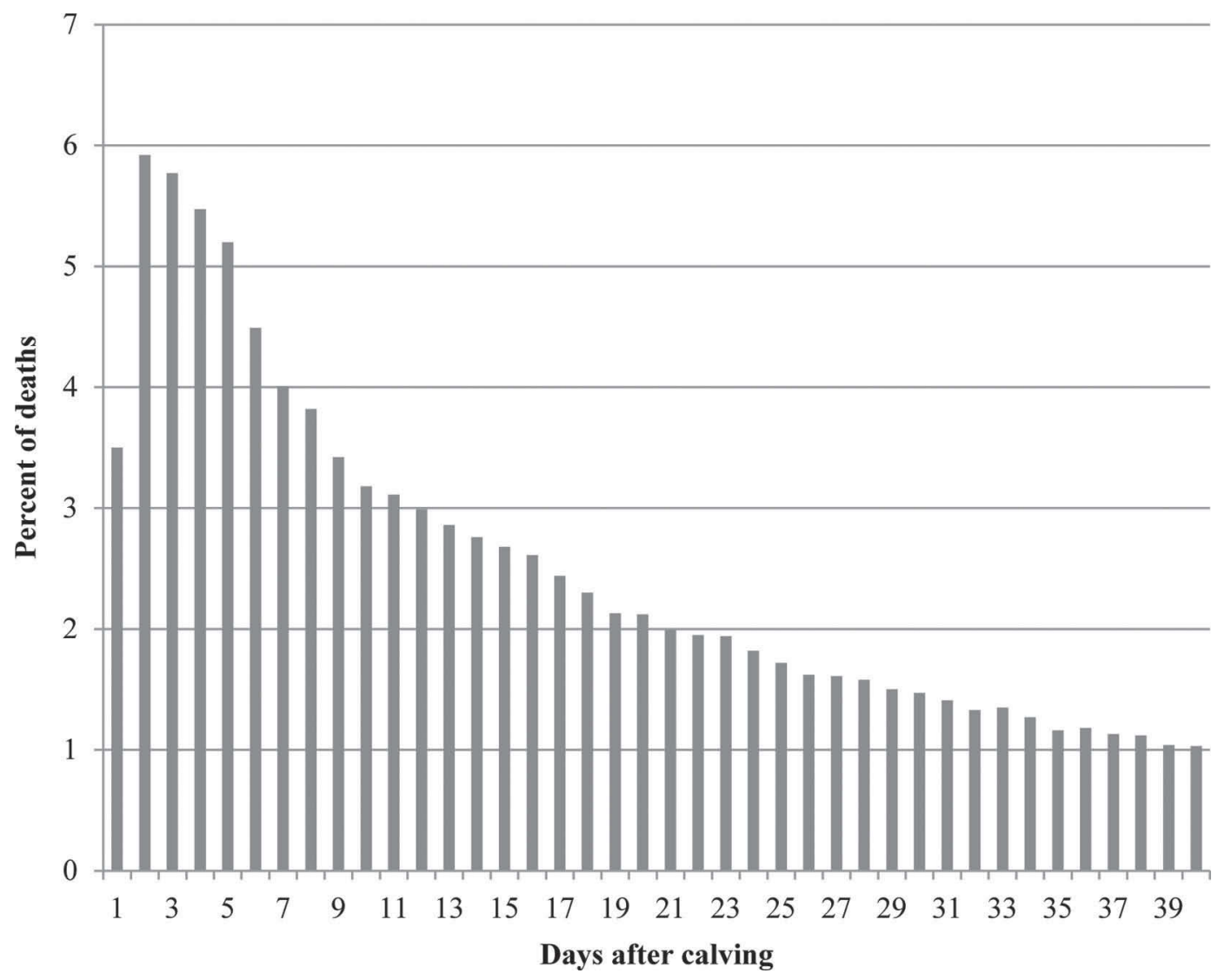

Figure 1. Distribution of deaths during the first $40 \mathrm{~d}$ after calving for cows in 7,188 Midwest DHIA herds from January 2006 to December 2010 .

Table 7. On-farm mortality risk factors for Midwest DHIA dairy herds (data from January 2006 to December 2010 for 7,188 herds)

\begin{tabular}{llcc}
\hline Variable & Category & Hazard ratio $^{1}$ & $95 \% \mathrm{CI}^{2}$ \\
\hline Cow-level risk factors & & & \\
First test-day milk yield $(\mathrm{kg})$ & Middle & & Ref $^{4}$ \\
& High & 1.0 & $0.934-0.961$ \\
& Low & 0.95 & $1.491-1.531$ \\
First test-day milk fat $\%$ & Middle & 1.51 & Ref \\
& High & 1.0 & $1.415-1.451$ \\
First test-day milk protein $\%$ & Low & 1.43 & $1.121-1.155$ \\
& Middle & 1.14 & Ref \\
& High & 1.0 & $0.940-0.967$ \\
Fat-to-protein ratio & Low & 0.95 & $1.361-1.398$ \\
& $1.0-1.6$ & 1.38 & Ref \\
First test MUN & $<1.0$ & 1.0 & $0.968-1.008$ \\
& $>1.6$ & 0.99 & $1.413-1.446$ \\
Parity & Middle & 1.43 & Ref \\
& High & 1.0 & $1.103-1.181$ \\
& Low & 1.14 & $1.130-1.196$ \\
& 1 & 1.16 & Ref \\
& 2 & 1.0 & $1.524-1.565$ \\
SCS & 3 & 1.54 & $2.084-2.143$ \\
& 4 & 2.11 & $2.463-2.543$ \\
& $\geq 5$ & 2.50 & $2.752-2.851$ \\
& $\leq 3.0$ & 2.80 & Ref \\
& $3.1-4.9$ & 1.0 & $1.086-1.112$ \\
& $5.0-5.9$ & 1.10 & $1.129-1.173$ \\
& $6.0-6.9$ & 1.15 & $1.146-1.198$ \\
& $\geq 7.0$ & 1.17 & $1.240-1.292$ \\
& & 1.27 & Continued
\end{tabular}


Table 7 (Continued). On-farm mortality risk factors for Midwest DHIA dairy herds (data from January 2006 to December 2010 for 7,188 herds)

\begin{tabular}{|c|c|c|c|}
\hline Variable & Category & Hazard ratio $^{1}$ & $95 \% \mathrm{CI}^{2}$ \\
\hline \multirow[t]{3}{*}{ Dry period (d) } & $31-70$ & 1.0 & Ref \\
\hline & $<30$ & 0.94 & $0.911-0.963$ \\
\hline & $>70$ & 1.08 & $1.064-1.095$ \\
\hline \multirow[t]{7}{*}{ Breed } & Holstein & 1.0 & Ref \\
\hline & Crossbred & 0.75 & $0.726-0.774$ \\
\hline & Brown Swiss & 0.86 & $0.816-0.900$ \\
\hline & Ayrshire & 0.85 & $0.774-0.939$ \\
\hline & Jersey & 0.79 & $0.767-0.813$ \\
\hline & Guernsey & 1.06 & $0.968-1.154$ \\
\hline & Others & 0.69 & $0.634-0.750$ \\
\hline \multirow[t]{5}{*}{ Calving difficulty score } & 1 & 1.00 & Ref \\
\hline & 2 & 1.03 & $1.009-1.050$ \\
\hline & 3 & 1.08 & $1.053-1.104$ \\
\hline & 4 & 1.09 & $1.042-1.134$ \\
\hline & 5 & 1.11 & $1.047-1.170$ \\
\hline \multirow[t]{2}{*}{ Calving with stillbirth } & No & 1.0 & Ref \\
\hline & Yes & 1.10 & $1.076-1.123$ \\
\hline \multirow[t]{2}{*}{ Twinning } & No & 1.0 & Ref \\
\hline & Yes & 1.07 & $1.045-1.092$ \\
\hline \multirow[t]{2}{*}{ Calf sex } & Female & 1.0 & Ref \\
\hline & Male & 1.02 & $1.012-1.032$ \\
\hline \multicolumn{4}{|l|}{ Herd-level risk factors } \\
\hline \multirow[t]{4}{*}{ Herd size $\left(\right.$ cow-years $\left.^{6}\right)$} & 20-99 & 1.0 & Ref \\
\hline & $100-199$ & 1.18 & $1.161-1.197$ \\
\hline & $200-499$ & 1.48 & $1.453-1.498$ \\
\hline & $>500$ & 1.92 & $1.889-1.947$ \\
\hline \multirow[t]{4}{*}{ Herd $305 \mathrm{ME}^{7}$ milk yield $(\mathrm{kg})$} & Low $^{8}$ & 1.0 & Ref \\
\hline & Medium low & 0.96 & $0.932-0.986$ \\
\hline & Medium high & 0.88 & $0.853-0.901$ \\
\hline & High & 0.77 & $0.747-0.791$ \\
\hline \multirow[t]{3}{*}{ Herd calving interval (mo) } & $12-13$ & 1.0 & Ref \\
\hline & $14-16$ & 1.16 & $1.144-1.170$ \\
\hline & $>16$ & 1.21 & $1.21-1.259$ \\
\hline \multirow[t]{5}{*}{ Herd SCC } & $\leq 2$ & 1.0 & Ref \\
\hline & $\overline{2} .1-2.5$ & 1.13 & $1.111-1.150$ \\
\hline & $2.6-3.0$ & 1.22 & $1.204-1.245$ \\
\hline & $3.1-3.5$ & 1.30 & $1.273-1.322$ \\
\hline & $\geq 3.6$ & 1.36 & $1.332-1.390$ \\
\hline \multirow[t]{4}{*}{ Herd stillbirth \% } & $\leq 5$ & 1.0 & Ref \\
\hline & $\overline{6}-15$ & 1.10 & $1.081-1.103$ \\
\hline & $16-25$ & 1.26 & $1.236-1.283$ \\
\hline & $>25$ & 1.40 & $1.339-1.453$ \\
\hline
\end{tabular}

${ }^{1}$ Hazard ratio $=$ hazard of having greater mortality rate; hazard ratios are adjusted for change in herd size.

${ }^{2}$ If $95 \%$ CI does not include 1 , it indicates statistically significant difference at $P<0.05$.

${ }^{3}$ Middle $=($ mean $\pm 1 \mathrm{SD})$, high $>($ mean $+1 \mathrm{SD})$, low $<($ mean $-1 \mathrm{SD})$.

${ }^{4}$ Reference category.

${ }^{5} \mathrm{MUN}$ middle $=($ mean \pm 6$)$, low $<($ mean -6$)$, high $>($ mean +6$)$.

${ }^{6} \mathrm{~A}$ cow that remains in the herd for 1 yr equals to 1 cow-year.

${ }^{7} 305 \mathrm{ME}=305$-d mature equivalent.

${ }^{8}$ Low $(<7,727 \mathrm{~kg})$, medium low $(\geq 7,727$ to $9,545 \mathrm{~kg})$, medium high $(\geq 9,546$ to $11,363 \mathrm{~kg})$, high $(\geq 11,364 \mathrm{~kg})$.

Calf Sex, Twinning, Stillbirth, and Calving Difficulty. Cows carrying males were at higher risk of mortality (Table 7 ). The mortality risk was $2 \%$ greater $(\mathrm{HR}=1.02 ; 95 \% \mathrm{CI}=1.01-1.03)$ for cows with male calves than cows with female calves. Twin births were also associated with increased mortality in dairy cows. The mortality risk was $7 \%$ greater $(\mathrm{HR}=1.07 ; 95 \%$ $\mathrm{CI}=1.04-1.09)$ among the cows that had twins than cows with singleton birth. Stillbirth was associated with mortality. The mortality hazard was $10 \%$ greater among cows that started their lactation with the event of stillbirth compared with cows that gave birth to a live calf. The increase in calving difficulty score was associated with increasing risk of on-farm mortality. The mortality risk was $8(\mathrm{HR}=1.08 ; 95 \% \mathrm{CI}=1.05-1.10), 9(\mathrm{HR}=$ $1.09 ; 95 \% \mathrm{CI}=1.04-1.13)$, and $11 \%(\mathrm{HR}=1.11 ; 95 \%$ 
SHAHID ET AL.

Table 8. Interaction analysis of first test-day milk with fat to protein ratio, parity, and breed for mortality risk $^{1}$

\begin{tabular}{|c|c|c|c|}
\hline Group variable & Contrast variable & Hazard ratio $^{2}$ & $95 \% \mathrm{CI}^{3}$ \\
\hline \multirow{4}{*}{$\begin{array}{l}\text { First test-day milk yield } \\
\text { Middle }^{4}\end{array}$} & Fat-to-protein ratio & & \\
\hline & $>1.6$ vs. $1.0-1.6$ & 1.32 & $1.292-1.332$ \\
\hline & $<1.0$ vs. $1.0-1.6$ & 1.01 & $0.982-1.032$ \\
\hline & $>1.6$ vs. $<1.0$ & 1.30 & $1.268-1.339$ \\
\hline \multirow[t]{3}{*}{ High } & $>1.6$ vs. $1.0-1.6$ & 1.06 & $1.020-1.101$ \\
\hline & $<1.0$ vs. $1.0-1.6$ & 1.02 & $0.966-1.073$ \\
\hline & $>1.6$ vs. $<1.0$ & 1.04 & $0.979-1.108$ \\
\hline \multirow[t]{3}{*}{ Low } & $>1.6$ vs. $1.0-1.6$ & 2.08 & $2.033-2.137$ \\
\hline & $<1.0$ vs. $1.0-1.6$ & 0.91 & $0.876-0.966$ \\
\hline & $>1.6$ vs. $<1.0$ & 2.26 & $2.153-2.381$ \\
\hline \multirow{7}{*}{$\begin{array}{l}\text { First test-day milk yield } \\
\text { Middle }\end{array}$} & Breed & & \\
\hline & Crossbred vs. Holstein & 0.78 & $0.752-0.813$ \\
\hline & Jersey vs. Holstein & 0.83 & $0.803-0.861$ \\
\hline & Ayrshire vs. Holstein & 0.88 & $0.784-1.003$ \\
\hline & Guernsey vs. Holstein & 0.99 & $0.885-1.116$ \\
\hline & Brown Swiss vs. Holstein & 0.87 & $0.822-0.926$ \\
\hline & Others vs. Holstein & 0.66 & $0.600-0.740$ \\
\hline \multirow[t]{6}{*}{ High } & Crossbred vs. Holstein & 0.79 & $0.713-0.871$ \\
\hline & Jersey vs. Holstein & 0.81 & $0.742-0.891$ \\
\hline & Ayrshire vs. Holstein & 0.94 & $0.688-1.302$ \\
\hline & Guernsey vs. Holstein & 1.08 & $0.817-1.433$ \\
\hline & Brown Swiss vs. Holstein & 1.04 & $0.899-1.209$ \\
\hline & Others vs. Holstein & 0.70 & $0.530-0.910$ \\
\hline \multirow[t]{6}{*}{ Low } & Crossbred vs. Holstein & 0.81 & $0.750-0.870$ \\
\hline & Jersey vs. Holstein & 0.78 & $0.750-0.831$ \\
\hline & Ayrshire vs. Holstein & 0.82 & $0.638-1.043$ \\
\hline & Guernsey vs. Holstein & 1.13 & $0.919-1.397$ \\
\hline & Brown Swiss vs. Holstein & 0.75 & $0.666-0.849$ \\
\hline & Others vs. Holstein & 0.82 & $0.680-1.000$ \\
\hline \multirow{11}{*}{$\begin{array}{l}\text { First test-day milk yield } \\
\text { Middle }\end{array}$} & Parity & & \\
\hline & 2 nd vs. 1 st & 1.57 & $1.542-1.591$ \\
\hline & 3rd vs. 1st & 2.20 & $2.165-2.242$ \\
\hline & 4th vs. 1 st & 2.71 & $2.661-2.763$ \\
\hline & 5 th vs. 1 st & 3.13 & $3.070-3.192$ \\
\hline & 3 rd vs. 2 nd & 1.40 & $1.381-1.432$ \\
\hline & 4 th vs. 2 nd & 1.73 & $1.693-1.764$ \\
\hline & 5th vs. 2 nd & 2.00 & $1.953-2.041$ \\
\hline & 4th vs. 3 rd & 1.23 & $1.213-1.250$ \\
\hline & 5 th vs. 3 rd & 1.42 & $1.393-1.451$ \\
\hline & 5 th vs. 4 th & 1.16 & $1.132-1.184$ \\
\hline \multirow{10}{*}{ High } & $2 \mathrm{nd}$ vs. $1 \mathrm{st}$ & 1.66 & $1.603-1.724$ \\
\hline & 3rd vs. 1st & 2.20 & $2.119-2.288$ \\
\hline & 4 th vs. 1 st & 2.59 & $2.475-2.710$ \\
\hline & 5th vs. 1 st & 3.04 & $2.882-3.205$ \\
\hline & 3rd vs. 2nd & 1.32 & $1.277-1.376$ \\
\hline & 4 th vs. 2 nd & 1.56 & $1.493-1.629$ \\
\hline & 5 th vs. 2 nd & 1.83 & $1.736-1.927$ \\
\hline & 4th vs. 3 rd & 1.18 & $1.124-1.232$ \\
\hline & 5 th vs. 3 rd & 1.38 & $1.309-1.456$ \\
\hline & 5th vs. 4 th & 1.17 & $1.107-1.244$ \\
\hline \multirow[t]{10}{*}{ Low } & 2 nd vs. 1 st & 1.52 & $1.473-1.570$ \\
\hline & 3rd vs. 1 st & 2.24 & $2.169-2.320$ \\
\hline & 4 th vs. 1 st & 2.60 & $2.501-2.703$ \\
\hline & 5 th vs. 1 st & 2.75 & $2.618-2.882$ \\
\hline & 3rd vs. 2nd & 1.48 & $1.429-1.524$ \\
\hline & 4 th vs. 2 nd & 1.71 & $1.647-1.779$ \\
\hline & 5 th vs. 2 nd & 1.81 & $1.724-1.898$ \\
\hline & 4 th vs. 3 rd & 1.16 & $1.115-1.206$ \\
\hline & 5th vs. 3 rd & 1.22 & $1.167-1.285$ \\
\hline & 5th vs. 4 th & 1.06 & $1.002-1.114$ \\
\hline
\end{tabular}

${ }^{1}$ Interaction of first test-day milk with fat to protein ratio, parity, and breed had $P<0.0001,<0.0001$, and 0.0553 , respectively.

${ }^{2}$ Hazard ratio $=$ hazard of having greater mortality rate. Hazard ratios are adjusted for herd size, herd $305-\mathrm{d}$ milk equivalent milk yield, herd calving interval, herd SCC, herd stillbirth percent, change in herd size, SCC calving difficulty, calf sex, and twinning.

${ }^{3}$ If $95 \%$ CI does not include 1 , it indicates statistically significant difference at $P<0.05$.

${ }^{4}$ Middle $=($ mean $\pm 1 \mathrm{SD})$, high $>($ mean $+1 \mathrm{SD})$, low $<($ mean $-1 \mathrm{SD})$. 
$\mathrm{CI}=1.05-1.17)$ greater for cows with calving difficulty score 3,4 and 5, respectively, compared with cows with calving difficulty score 1 .

Breed and Parity. On-farm MR varied among breeds. Holstein had significantly higher mortality hazard than Jersey, Ayrshire, Brown Swiss, and crossbreds. Only Guernsey had numerically higher mortality than Holstein (not statistically significant). Crossbreds, Jersey, Ayrshire, and Brown Swiss had 25, 21, 15, and $14 \%$ lower mortality risk than Holstein, respectively (Table 7). Interaction of 1st MY with breed was not significant at all 3 levels of milk yield (Table 8). Mortality hazard in dairy cows increased with increase in parity. The risk for on-farm mortality among cows in parities 2 , 3 , 4, and 5 was 54,111, 150 , and $180 \%$ greater than for cows in parity 1 , respectively (Table 7 ). Interaction analysis of 1st MY with parity was significant at all 3 levels of milk yield. Although the risk of mortality increased with parity, the association of mortality with parity was stronger in average- and low-producing cows as compared with high-producing cows, as shown in Table 8.

\section{Herd-Level Risk Factors}

Milk Yield, Herd Size, and HCI. Greater herdlevel milk yield was associated with decreased mortality. Mortality hazard was 23, 12 , and $4 \%$ lower among cows in herds with high $(\geq 11,364 \mathrm{~kg})$, medium high $(\geq 9,546$ to $<11,364 \mathrm{~kg})$, and medium low $(7,727-9,545$ $\mathrm{kg}$ ) yield compared with cows in herds with low milk yield $(<7,727 \mathrm{~kg})$, respectively (Table 7$)$. Cow in larger herds had a higher risk for mortality. Mortality risk for cows in larger herds ( $\geq 500$ cow-years) was $92 \%$ higher, in high medium herds (200-499 cow-years) $48 \%$ higher, and in low medium herds (100-199 cow-years) $18 \%$ higher than for cows in small herds $(<100$ cow-years; Table 7). As the HCI increased, mortality among cows increased. Cows in herds with longer HCI ( $>16 \mathrm{mo}$ ) had $21 \%$ higher risk and with 15 to 16 mo had $16 \%$ higher mortality risk than cows in herds with reference HCI (12-14 mo; Table 7).

HSCS and Herd Stillbirth. Mortality hazard increased with greater HSCS (Table 7). Mortality hazard was $13,22,30$, and $36 \%$ higher for herds with low medium (HSCS $=2.1$ to 2.5 ), medium (2.6 to 3.0 ), medium high (3.1 to 3.5$)$, and high $(\geq 3.6)$ HSCS compared with herds with low HSCS $(\leq 2.0)$, respectively. Herds with higher HSB had higher mortality. Mortality hazard was 40 and $26 \%$ higher in herds with high HSB $(>25 \%)$ and medium high HSB (16 to 25\%) compared with herds with low HSB $(\leq 5 \%)$, respectively.

\section{DISCUSSION}

\section{Mortality Statistics}

Mortality rate in our study was in close agreement with recent studies. Pinedo et al. (2010) studied approximately 3.6 million lactation records from 2,054 US dairy herds, primarily east of Mississippi river with herd size greater than 100 cows, and reported a yearly MR of $6.6 \%$ for the period of 2001 to 2006. Mortality rate in our study was slightly lower than that in Pinedo et al. (2010), possibly because we included herds with $<100$ cow-years and their study excluded the smaller herds (herds size $<100$ ) and smaller herds tended to have lower mortality. Similarly, Miller et al. (2008) reported that death frequency was $5.7 \%$ per cow for the period of 1995 to 2005. Likewise, Alvåsen et al. (2012) studied the data for all Swedish dairy herds enrolled in the milk-recording scheme between 2002 and 2010 and reported that the MR, for herds with a herd size $\geq 20$ cows, gradually increased from 5.1 events per 100 cow-years in 2002 to 2003 to 6.6 in 2009 to 2010. Our current findings are supported by recent studies showing a consistent increase in mortality over time, and we suggest that on-farm mortality is an issue that deserves more attention as it has economic and animal welfare implications. Some of the increase in MR could also be attributed to a greater number of cows being euthanized on farm today rather than sent to slaughter due to newer regulations on transportation of nonambulatory animals.

A higher MR for cows in early lactation has been previously reported. Raboisson et al. (2011) found that approximately 35 and $55 \%$ of the deaths occurred during the first 30 and 100 DIM, respectively. Pinedo et al. (2010) reported that mortality was the primary reported cause of leaving the herd during the first 100 DIM and that the proportion of cows that died among total culled cows decreased from 57 to $22 \%$ from 1 to 100 DIM. Miller et al. (2008) reported that death frequency was highest $(17.3 \%)$ in early lactation $(\leq 45$ DIM), followed by 46 to 90 (10.1\%), 91 to 150 (8.5\%), 150 to $250(6.5 \%)$, and $\geq 251$ DIM $(0.9 \%)$. The transition period (approximately $3 \mathrm{wk}$ before and $3 \mathrm{wk}$ after calving) is a high-risk period for many health disorders. During this period a cow undergoes tremendous metabolic and endocrine changes related to parturition and the onset of lactation. If the homeostatic mechanisms of the cow do not act effectively to respond to the changes in the body, disorders such as clinical hypocalcemia, ketosis, retained fetal membranes, metritis, mastitis, and displacement of the abomasum may occur (Goff and Horst, 1997). Some diseases that become clinically 
apparent in later stages of lactation, such as laminitis, ovarian cysts, endometritis, and anestrus, are related to the early postpartum period (Goff and Horst, 1997). Managing transition cows successfully may reduce MR in dairy farms.

The range in herd-level MR in the current study was in agreement with Raboisson et al. (2011), who reported MR from 0 to $98.4 \%$. The proportion of herds with yearly zero mortality in our study was comparatively lower than the proportion reported by Raboisson et al. (2011), where $33 \%$ of herds had zero mortality. Thomsen et al. (2006a) reported $26.9 \%$ out of 6,839 Danish dairy herds with zero percent mortality. The proportion of herds with higher yearly mortality $(\geq 10 \%)$ was in close agreement to Raboisson et al. (2011), where they found that 90th percentile and above herds had MR of about $10 \%$. This distribution of herd-level mortality from 0 to $>10 \%$ indicates there is room for improvement and MR can be reduced. In addition, a certain degree of error is inherent, as DHI data sets are derived from producer-reported information.

The results of frequency distribution for reasons of culling are in agreement with the findings reported by Pinedo et al. (2010). In their data, the primary reason for cow removal was death (20.6\% of total culling), followed by reproduction (17.7\%), injury or other (14.3\%), and low production and mastitis (both $12.1 \%$ ). Previous studies had shown mortality as a lesser reason for culling. Hadley et al. (2006) analyzed the DHIA records from 1993 to 1999 and reported that injury or others (26.9\% of total culls) was the primary reason for culling followed by reproduction (18.9\%), low production (12.8\%), mastitis (12.1\%), and then mortality (10.6\%). Smith et al. (2000) analyzed the DHIA records for the year 1998 and found that, for the northern states of the United States, injury or other was the most common reason for culling (25.8\% of total culls) followed by reproduction $(17.1 \%)$, death $(14.8 \%)$, and mastitis $(11.9 \%)$. We included these data on culling reasons to demonstrate that it appears that the ranking of mortality as culling reason has gradually increased over time; this is cause for concern.

\section{Cow-Level Risk Factors}

Milk Yield, FPR, Fat Percent, and Protein Percent. Lower mortality in high-producing cows corresponds with findings of Pinedo et al. (2010), who reported that the annualized MR was lower $(2.7 \%)$ for cows with cow-relative $305 \mathrm{ME}$ milk yield $>2,187 \mathrm{~kg}$ than cows with cow-relative 305ME milk yield $<-2,313$ $\mathrm{kg}$ (mortality of 9.9\%). Similarly, Hadley et al. (2006) reported that cows producing $45 \mathrm{~kg}$ more milk than the average $305 \mathrm{ME}$ milk yield were $1.7 \%$ less likely to be culled in the upper Midwest region than the averageproducing cow. In contrast, Miller et al. (2008) found that death frequency increased $0.4 \%$ when the average milk yield per cow increased by $1,000 \mathrm{~kg}$ in Holsteins. Although the genetic correlation between milk yield and cow survival has been shown to be slightly negative and phenotypic correlation positive (Dematawewa and Berger, 1998); this apparent decrease in mortality with greater milk yield could be due to the preferential treatment by the dairy producer toward the high-producing cows compared with the low-producing cows (Dematawewa and Berger, 1998), and it could also be suggested that the physiological stress of high milk yield is not necessarily harmful to the welfare of a dairy cow. Cows with lower milk yield at the first test day had higher mortality hazard. Most likely these cows started their lactation with some disorders related to the transition period and could not survive in that lactation.

The higher incidence of mortality among cows with high FPR (>1.6) is consistent with Toni et al. (2011), who analyzed lactation survival and found that culling hazard was significantly higher among cows with early postpartum FPR $\geq 2$ than cows with FPR 1.0 to 1.5. Mortality accounted for $11 \%$ of total culls in their study. Greater FPR $(>1.5,>2.0)$ in early lactation has been associated with increased risk for retained placenta, left-displaced abomasum, metritis and clinical endometritis, ketosis, ovarian cyst, lameness, and mastitis (Heuer et al. 1999; Toni et al., 2011). An FPR of greater than 1.5 is an indicative of energy deficiency (Duffield et al., 1997; Heuer et al., 1999). This energy deficiency or negative energy balance predisposes cows to various postpartum disorders, which might explain the increased mortality in cows with greater FPR in early lactation. The lower mortality risk due to high FPR $(>1.6)$ in high-producing cows as compared with middle- and low-producing cows further supports the preferential treatment of farmers to high-producing cows. Such cows might have better chances to be diagnosed and treated in time instead of dying on the farm.

The increased mortality hazard associated with high and low milk fat percent is likely related to fat mobilization. High fat percent is an indicative of subclinical and clinical ketosis (Duffield et al., 1997), and subclinical ketosis increases the risk of culling and mortality. Low milk fat has been associated with subacute ruminal acidosis (Nordlund et al., 1995). Early transition cows are at higher risk for acidosis due to reduced absorptive capacity of the rumen, poorly adapted rumen microbial population, and the rapid introduction to high-energy density diets (Dirksen et al., 1985).

Favorable association of high milk protein with mortality could be the result of better energy intake, as 
milk protein content can be affected by energy intake in lactating dairy cows (Sato, 1998). Low milk protein concentration $(<2.7 \%)$ has been associated with negative energy balance (Duchateau et al., 2005). During early lactation, cows are already in negative energy balance and a further decline in dietary energy might aggravate the state of negative energy balance and, thus, predispose cows to different metabolic disorders thereby increasing mortality hazard in cows with low milk protein.

SCS and MUN. The increase in mortality with increasing SCS is in agreement with the findings of Thomsen et al. (2006a), who reported a $16 \%$ increase in herd mortality for every $100,000 \mathrm{cell} / \mathrm{mL}$ increase in SCC. The increase in SCS has been shown to be associated with cases of clinical mastitis, and clinical mastitis has been associated with increased risk of mortality in dairy cows (Hertl et al., 2011).

Cow mortality has been associated with higher MUN values. One of the common reasons for elevated MUN is excessive protein intake (Nousiainen et al., 2004). The increased mortality hazard for cows with elevated MUN could be due to increased energy deficit, as the excess protein intake could exacerbate the negative energy balance because of the extra energy required to detoxify and excrete urea.

Dry Period and Calving Interval. Lower mortality with shorter dry period is in accordance with the study of Pinedo and De Vries (2010) who observed 37\% lower odds of mortality in cows with shorter dry period $(<41 \mathrm{~d})$ than cows with longer dry period $(>71 \mathrm{~d})$. Shorter dry period was associated with decreased incidence of IMI (Pinedo et al., 2011). Additionally, short dry period strategy ( 26 vs. 56 d) resulted in improved energy balance and decreased fat mobilization during the first month of lactation (Rastani et al., 2005). Improved energy balance and low incidence of diseases such as mastitis and ketosis might explain the reduced mortality among cows with short dry period, as mastitis has been associated with increased mortality in dairy cows (Hertl et al., 2011). In our study, longer dry period was associated with higher mortality, which is in consistent with Pinedo and De Vries (2010). Longer dry period may increase the risk of overconditioning, which increases the risk for metabolic disorders around calving (Heuer et al., 1999) and thus may increase the mortality risk in those cows.

Increased mortality with longer calving interval is in agreement with the findings of McConnel et al. (2008), who reported that herds with an average calving interval $>13.9$ mo were 1.78 times more likely to have a greater level of mortality than herds with an average calving interval of $\leq 12.9$ mo. Overconditioning could be one reason for higher mortality in cows with longer calving interval; as mentioned previously, these cows might be more at risk for metabolic disorders during the dry period (Heuer et al., 1999).

Stillbirth, Twinning, Calf Sex, and Calving Difficulty. The higher risk of mortality in cows starting their lactation with stillbirth is in agreement with the findings of Bicalho et al. (2007). They reported that cows that had stillbirth were at $41 \%$ increased hazard of death or culling from the herd than cows that had live calves. Cows experiencing stillbirth have increased risk of different postpartum disorders, such as prolapsed uterus, retained placenta, metritis, and displaced abomasum (Correa et al., 1993). The higher incidence of these postpartum disorders may be associated with decreased survival of such cows (Bicalho et al., 2007).

Similar to the findings of present study, Bicalho et al. (2007) observed that cows that calved with twins had $42 \%$ higher hazard of death or culling than those with singletons. The increased risk of mortality among cows carrying twins might be the result of problems such as increased incidence of dystocia, retained placenta, metritis (Bell and Roberts, 2007), displaced abomasum, and ketosis (Fricke, 2001).

Male calves have been reported to be a risk factor for different reproductive disorders, such as stillbirth (Bicalho et al., 2007) and dystocia (Atashi et al., 2012), and these disorders have been associated with increased risk of mortality among dairy cows (Dematawewa and Berger, 1998; Bicalho et al., 2007). Increased risk of mortality with increasing calving difficulty score is supported by previous studies. Dematawewa and Berger (1998) observed that cows with calving difficulty score 5 (extreme calving difficulty) had $4 \%$ higher mortality than cows with score 1 (calving without assistance). Similarly, Bicalho et al. (2007) found that cows with calving difficulty score 3 and 4 had $20 \%$ higher hazard of death or culling than cows with calving difficulty score 1 and 2 .

Breed and Parity. Mortality variation among the breeds has been documented before. Raboisson et al. (2011) observed higher mortality in Holstein compared with Montbeliarde and Normande in France. Similarly, Thomsen et al. (2006a) reported a higher mortality in Danish Holstein compared with Danish Jersey, Danish Red, or other breeds (Ayrshire and crossbreds). Likewise, it has also been reported that crossbred cows have better survivability than purebred Holstein cows (Heins et al., 2006). The interaction of 1st MY with breed was nonsignificant because 1st MY was estimated on a herd year-season basis that did not allow the crossbreed comparison. Our study found lower MR with higher herd-level milk yield across breeds and high 1st MY was also protective for mortality. Further research is 
needed to investigate factors responsible for differences in cow survivability besides milk production levels.

The higher MR with increasing parity has been reported previously (Miller et al., 2008; Pinedo et al., 2010; Raboisson et al., 2011) and the increased incidence of certain diseases in older cows might be the reason for increased mortality among these animals. The relatively lower MR with increasing parity among high-producing cows compared with middle- and lowproducing cows could be attributed to the farmers' attentiveness for high-producing cows, as described earlier.

\section{Herd-Level Risk Factors}

Milk Yield, Herd Size, and HCI. Decreased mortality with increased herd-level milk yield is in agreement with what has been reported in previous studies. Alvåsen et al. (2012) described a 12,10, and $3 \%$ decrease in MR in herds with milk yield $\geq 9,981,9,291$ to 9,980 $\mathrm{kg}$, and 8,525 to $9,290 \mathrm{~kg}$, respectively, compared with herds with milk yield $<8,525 \mathrm{~kg}$. Similarly, Thomsen et al. (2006a) documented a $7 \%$ decrease (odds ratio: $0.93)$ in mortality for every $1,000 \mathrm{~kg}$ increase in mean milk yield per cow-year. Smith et al. (2000) observed a decrease in mortality from 7.7 to $7.1 \%$ and $5.9 \%$ for low- $(<7,258 \mathrm{~kg})$, medium- $(7,258$ to $9,072 \mathrm{~kg})$, and high- $(>9,072 \mathrm{~kg})$ producing herds, respectively. Better management practices probably contribute to increased milk yield; therefore, lower mortality in high-producing herds could be the cumulative effect of good management practices (Thomsen et al., 2006a; Alvåsen et al., 2012).

In our study, mortality increased with increasing herd size; this agrees with Alvåsen et al. (2012), who described lower MR (6.0\%) for smaller herds (herd size, 50-99.9 cow-years) and the highest MR (7.5\%) for larger herds ( $\geq 200$ cow-years). Likewise, Raboisson et al. (2011) reported a $2 \%$ change in cow mortality for every 10 cow-years increase in herd size. In addition, Pinedo et al. (2010) documented MR of $5.8 \%$ for herds of 100 to 200 cows and $9.6 \%$ for herds $>3,000$ cows. Larger herd size has been correlated with less attention to individual cows (Nørgaard et al., 1999). Along with other dynamics, the lower amount of time spent on individual cows in larger herds could be one of the factors for increased mortality, as in these herds, problem or at-risk cows might not be identified in time for treatment or culling, thereby increasing on-farm mortality. This implies that improving the individual attention per cow through proper labor management or the use of precision dairy farming technologies for individual animal monitoring could be helpful to reduce MR in larger herds.
In agreement with our study, Alvåsen et al. (2012) observed that the risk of mortality was $22 \%$ higher in herds with a calving interval $\geq 422.0 \mathrm{~d}$ compared with the herds with calving interval of 389.3 d. Likewise, Raboisson et al. (2011) reported a 1\% change in cow mortality for every $10 \mathrm{~d}$ increase in calving interval. Herd-level calving interval is an indirect reflection of good management (Alvåsen et al., 2012). High levels of quality management are needed to achieve a low average calving interval (Raboisson et al., 2011; Alvåsen et al., 2012), which might have beneficial effects on lowering cattle mortality in herds with a short calving interval.

HSCS and Herd Stillbirth. Higher mortality with increasing HSCS is in accordance with the study of Thomsen et al. (2006a), who reported a 16\% increase in the risk of mortality for every $100,000 \mathrm{cell} / \mathrm{mL}$ increase in herd average SCC. Good management (clean and accurate vs. quick and dirty) was associated with reduced bulk milk SCC (Barkema et al., 1999) and could explain the lower MR in herds with lower SCS. Barkema et al. (1999) indicated that the most important difference between farmers of herds with low and high bulk milk SCC was that the former worked precisely rather than fast whereas the latter worked quickly rather than precisely, resulting in the definitions of clean and accurate versus quick and dirty, respectively.

The findings of the current study showed that mortality was higher in herds with higher HSB, which is in agreement with Thomsen et al. (2006b), who studied the risk factors for cows more prone to morbidity and mortality (problem cows) and found that every 5\% increase in the proportion of stillborn calves was associated with a $40 \%$ increase in problem cows. They used the herd-level stillbirth as indicative of management level. The overall findings of herd-level risk factors strongly support the concept of quality management to reduce dairy cow mortality.

\section{CONCLUSIONS}

On-farm cow mortality in Midwest DHIA dairy herds increased from 2006 to 2010. More cows died in early lactation and mortality was the main reason for cows leaving the herds. Increased mortality in cows was associated with the first test-day higher FPR, higher milk fat percent, lower milk protein percent, higher MUN, higher SCS, longer calving interval, multiple calves, male calves, increased calving difficulty score, and increasing parity. Mortality risk was lower for cows with higher first test-day milk yield and higher milk protein percent. Mortality hazard was greater in herds with larger herd size, higher SCS, increased percentage of stillbirths, and increased calving interval, and lower in 
herds with higher average milk production. The first test-day yield records could be helpful to identify cows at higher risk for mortality, although many cows die before first test day. However, we could conclude that the cumulative effects of cow- and herd-level risk factors indicate that quality management in the transition period would be useful to reduce MR in Midwest dairy herds.

\section{ACKNOWLEDGMENTS}

The authors thank Dairy Records Management Systems (Raleigh, NC) for kindly providing the DHIA data set. M. Q. Shahid was supported by the Higher Education Commission of Pakistan (Islamabad).

\section{REFERENCES}

Alvåsen, K., M. Jansson Mörk, C. Hallén Sandgren, P. T. Thomsen, and U. Emanuelson. 2012. Herd-level risk factors associated with cow mortality in Swedish dairy herds. J. Dairy Sci. 95:4352-4362.

Atashi, H., A. Abdolmohammadi, M. Dadpasand, and A. Asaadi. 2012. Prevalence, risk factors and consequent effect of dystocia in Holstein dairy cows in Iran. Asian-Aust. J. Anim. Sci. 25:447-451.

Barkema, H. W., J. D. Van der Ploeg, Y. H. Schukken, T. J. G. M. Lam, G. Benedictus, and A. Brand. 1999. Management style and its association with bulk milk somatic cell count and incidence rate of clinical mastitis. J. Dairy Sci. 82:1655-1663.

Bell, M. J., and D. J. Roberts. 2007. Effect of twinning on the feed intake, performance and health of dairy cows. Livest. Sci. 107:274281.

Bicalho, R. C., K. N. Galvao, S. H. Cheong, R. O. Gilbert, L. D. Warnick, and C. L. Guard. 2007. Effect of stillbirth on dam's survival and reproduction performance in Holstein dairy cows. J. Dairy Sci. 90:2797-2803.

Correa, M. T., H. Erb, and J. Scarlett. 1993. Path analysis of seven postpartum disorders of Holstein cows. J. Dairy Sci. 76:13051312 .

Dairy Records Management Systems (DRMS). 2012. DHI Report Options Fact Sheet - 6/12. Accessed Dec. 5, 2012. http://www.drms. org/PDF/materials/optman.pdf.

Dematawewa, C. M., and P. J. Berger. 1998. Genetic and phenotypic parameters for 305-day yield, fertility, and survival in Holsteins. J. Dairy Sci. 81:2700-2709.

Dirksen, G., H. Liebich, and H. Mayer. 1985. Adaptive changes of the ruminal mucosa and functional and clinical significance. Bovine Pract. 20:116-120.

Duchateau, L., G. Opsomer, J. Dewulf, and P. Janssen. 2005. The non-linear effect (determined by the penalized partial-likelihood approach) of milk-protein concentration on time to first insemination in Belgian dairy cows. Prev. Vet. Med. 68:81-90.

Duffield, T. F., D. F. Kelton, K. E. Leslie, K. D. Lissemore, and J. H. Lumsden. 1997. Use of test day milk fat and milk protein to detect subclinical ketosis in dairy cattle in Ontario. Can. Vet. J. 38:713-718.

European Food Safety Authority (EFSA). 2012. Scientific opinion on the use of animal-based measures to assess welfare of dairy cows. EFSA J. 2554:1-81.

Fricke, P. M. 2001. Review: Twinning in dairy cattle. Prof. Anim. Sci. 17:61-67.

Goff, J. P., and R. L. Horst. 1997. Physiological changes at parturition and their relationship to metabolic disorders. J. Dairy Sci. 80:1260-1268.

Hadley, G. L., C. A. Wolf, and S. B. Harsh. 2006. Dairy cattle culling patterns, explanations, and implications. J. Dairy Sci. 89:22862296.
Heins, B. J., L. B. Hansen, and A. J. Seykora. 2006. Calving difficulty and stillbirths of pure Holsteins versus crossbreds of Holstein with Normande, Montbeliarde, and Scandinavian Red. J. Dairy Sci. 89:2805-2810.

Hertl, J. A., Y. H. Schukken, D. Bar, G. J. Bennett, R. N. González, B. J. Rauch, F. L. Welcome, L. W. Tauer, and Y. T. Gröhn. 2011. The effect of recurrent episodes of clinical mastitis caused by gram-positive and gram-negative bacteria and other organisms on mortality and culling in Holstein dairy cows. J. Dairy Sci. 94:4863-4877.

Heuer, C., Y. H. Schukken, and P. Dobbelaar. 1999. Postpartum body condition score and results from the first test day milk as predictors of disease, fertility, yield, and culling in commercial dairy herds. J. Dairy Sci. 82:295-304.

McConnel, C. S., J. E. Lombard, B. A. Wagner, and F. B. Garry. 2008. Evaluation of factors associated with increased dairy cow mortality on United States dairy operations. J. Dairy Sci. 91:1423-1432.

Miller, R. H., M. T. Kuhn, H. D. Norman, and J. R. Wright. 2008. Death losses for lactating dairy cows in herds enrolled in dairy herd improvement test plans. J. Dairy Sci. 91:3710-3715.

Minnesota Dairy Herd Improvement Association (MN-DHIA). 2011. DHI Yardstick for 2011-Rolling Herd Averages. Accessed Apr. 7, 2011. http://www.mndhia.org/annualsummary/yardstick11.pdf.

Nordlund, K. V., E. F. Garrett, and G. R. Oetzel. 1995. Herd based rumenocentesis: A clinical approach to the diagnosis of subacute rumen acidosis. Compend. Contin. Educ. Pract. Vet. 17:S48-S56.

Nørgaard, N. H., K. M. Lind, and J. F. Agger. 1999. Cointegration analysis used in a study of dairy cow mortality. Prev. Vet. Med. 42:99-119.

Nousiainen, J., K. J. Shingfield, and P. Huhtanen. 2004. Evaluation of milk urea nitrogen as a diagnostic of protein feeding. J. Dairy Sci. 87:386-398.

Pinedo, P. J., and A. De Vries. 2010. Effect of days to conception in the previous lactation on the risk of death and live culling around calving. J. Dairy Sci. 93:968-977.

Pinedo, P. J., A. De Vries, and D. W. Webb. 2010. Dynamics of culling risk with disposal codes reported by Dairy Herd Improvement dairy herds. J. Dairy Sci. 93:2250-2261.

Pinedo, P., C. Risco, and P. Melendez. 2011. A retrospective study on the association between different lengths of the dry period and subclinical mastitis, milk yield, reproductive performance, and culling in Chilean dairy cows. J. Dairy Sci. 94:106-115.

Raboisson, D., E. Cahuzac, P. Sans, and G. Allaire. 2011. Herd-level and contextual factors influencing dairy cow mortality in France in 2005 and 2006. J. Dairy Sci. 94:1790-1803.

Rastani, R. R., R. R. Grummer, S. J. Bertics, A. Gumen, M. C. Wiltbank, D. G. Mashek, and M. Schwab. 2005. Reducing dry period length to simplify feeding transition cows: milk production, energy balance, and metabolic profiles. J. Dairy Sci. 88:1004-1014

Sato, H. 1998. Correlation between milk urea and plasma metabolites and milk fat and protein concentrations in dairy cows. J. Jpn. Vet. Med. Assoc. 51:242-245.

Shahid, M. Q. 2013. Cow mortality in Midwest dairy herds. PhD Diss. University of Minnesota, St. Paul.

Smith, J. W., L. O. Ely, and A. M. Chapa. 2000. Effect of region, herd size, and milk production on reasons cows leave the herd. J. Dairy Sci. 83:2980-2987.

Thomsen, P. T., and H. Houe. 2006. Dairy cow mortality: A review. Vet. Q. 28:122-129.

Thomsen, P. T., A. M. Kjeldsen, J. T. Sorensen, H. Houe, and A. K. Ersboll. 2006a. Herd- level risk factors for the mortality of cows in Danish dairy herds. Vet. Rec. 158:622-626.

Thomsen, P. T., S. Østergaard, H. Houe, and J. T. Sørensen. 2006b. Loser cows in Danish dairy herds: Risk factors. Prev. Vet. Med. 79:136-154.

Toni, F., L. Vincenti, L. Grigoletto, A. Ricci, and Y. H. Schukken. 2011. Early lactation ratio of fat and protein percentage in milk is associated with health, milk production, and survival. J. Dairy Sci. 94:1772-1783. 